\title{
CNTN-1 Enhances Chemoresistance in Human Lung Adenocarcinoma Through Induction of Epithelial-Mesenchymal Transition by Targeting the PI3K/Akt Pathway
}

\author{
Ruijie Zhang ${ }^{a}$ Shenghua Sun ${ }^{a}$ Fuyun Jib Chun Liu ${ }^{a}$ Hua Lin ${ }^{a}$ Lihua Xie $^{a}$ \\ Honghui Yang ${ }^{a}$ Wenxiang Tang ${ }^{a}$ Yan Zhou ${ }^{a}$ Jianping $X u^{c}$ Pei Lid,e

\begin{abstract}
aDepartment of Respiratory Medicine, the Third Xiangya Hospital, Central South University, Changsha, Hunan, ${ }^{b}$ Institute of Human Respiratory Disease, Xinqiao Hospital, Third Military Medical University, Chongqing, 'Department of Pathology, Xinqiao Hospital, Third Military Medical University, Chongqing, ${ }^{\mathrm{d} D e p a r t m e n t}$ of Orthopedic Surgery, No. 89 hospital of PLA, Weifang, Shandong, eDepartment of Orthopedic Surgery, Southwest Hospital, Third Military Medical University, Chongqing, China
\end{abstract}

\section{Key Words}

CNTN-1 • EMT • Chemoresistance $・ P I 3 K / A k t \cdot N S C L C$

\begin{abstract}
Background/Aims: Chemoresistance has been a major obstacle to the effective treatment of lung cancer. Previously, we found that contactin-1 (CNTN-1) is related to cisplatin resistance in lung adenocarcinoma. Here, we aimed to investigate the underlying mechanism behind the role of CNTN-1 in cisplatin resistance in lung adenocarcinoma. Methods: EMT-associated phenotypes, including alterations in cellular morphology and marker (E-cadherin, $\mathrm{N}$-cadherin and Vimentin) expression, were compared between A549 cells and A549/DDP cells (a cisplatinresistant cell line of lung adenocarcinoma with abnormal CNTN-1 expression) by using realtime time PCR and Western blotting. Other methods, including CNTN-1 overexpression in A549 cells and CNTN-1 knockdown in A549/DDP cells, were also used to investigate the role of CNTN-1 in mediating the EMT phenotype and thr resulting cisplatin resistance and malignant progression of cancer cells in vitro and in vivo. Results: A549/DDP cells exhibited an EMT phenotype and aggravated malignant behaviors. CNTN-1 knockdown in A549/DDP cells partly reversed the EMT phenotype, increased drug sensitivity, and attenuated the malignant progression whereas CNTN-1 overexpression in A549 cells resulted in the opposite trend. Furthermore, the PI3K/Akt pathway was involved in the effects of CNTN-1 on EMT progression in A549/DDP cells, verified by the xenograft mouse model. Conclusion: CNTN-1 promotes cisplatin resistance in human cisplatin-resistant lung adenocarcinoma through inducing the EMT process by activating the PI3K/Akt signaling pathway. CNTN-1 may be a potential therapeutic target to reverse chemoresistance in cisplatin-resistant lung adenocarcinoma.
\end{abstract}




\section{Cellular Physiology Cell Physiol Biochem 2017;43:465-480 \begin{tabular}{l|l|l} 
and Biochemistry Published online: September 19, 2017 & $\begin{array}{l}\text { (c) } 2017 \text { The Author(s). Published by S. Karger AG, Base } \\
\text { www.karger.com/cpb }\end{array}$ \\
\hline
\end{tabular} \\ Zhang et al.: CNTN-1 Enhances Chemoresistance through Inducing EMT in Human Lung Adenocarcinoma}

\section{Introduction}

Lung cancer, particularly non-small cell lung cancer (NSCLC), remains a challenging disease with high mortality worldwide [1-2]. Despite the tremendous mountainous progress in multidisciplinary therapy, the overall 5-year survival rate is still poor [3]. One of the major obstacles restricting therapeutic efficiency is intrinsic or acquired resistance to chemotherapeutic agents in clinical practice [4-8]. To explore the mechanism of acquired multidrug resistance (MDR) to cisplatin, a number of studies have been carried out, and the accumulating data have displayed that an increase in drug efflux, DNA damage repair, activation of a detoxification system against the chemotherapeutic regimen, and apoptosis resistance are the main mechanisms of MDR [8-11], which have helped us to promote treatment efficiency for patients with cancer to a certain extent.

Recently, several studies have suggested a close relationship between epithelialmesenchymal transition (EMT) progression and chemoresistance in multiple cancer cells [12-14], which shed light on advancing the treatment efficiency for cancer patients. EMT is a critical step during embryo development, wound healing, tissue fibrosis, tumor migration, and invasion [15-16]. As a dynamic and reversible process, the EMT progression, characterized by an alteration in cellular morphology, enhancement in the mobile ability, formation of a cancer stem cell (CSC) phenotype, and acquisition of anoikis resistance, was detected in certain drug-resistant cancer cells such as hepatocellular carcinoma [17], colorectal cancer [18], nasopharyngeal carcinoma [19], and breast cancer [20]. Concomitantly, downregulation of the epithelial marker (E-cadherin) and upregulation of mesenchymal markers (vimentin, $\mathrm{N}$-cadherin, fibronectin) and other related transcription factors (snail, slug, and twist) were also found in drug-resistant cancer cells with an EMT phenotype [12]. Additionally, the complex EMT process was reported to be related to the PI3K/Akt signaling pathway [21-24], which also participated in the cisplatin resistance of many cancer cells, including colorectal cancer [25], lung cancer [26], and ovarian cancer [27]. However, whether the EMT process is correlated with cisplatin resistance in NSCLC is still unclear.

Contactin-1 (CNTN-1), a neuronal cell adhesion molecular, has been shown to be involved in nervous system development [28-29]. In recent years, the abnormal expression of CNTN-1 was reported to be closely correlated with carcinogenesis and tumor progression [11, 30-34]. Furthermore, the elevated expression of CNTN-1 was demonstrated to facilitate metastasis of MKN45 gastric cancer cells via activation of the EMT process [35]. Additionally, in our previous study, silencing CNTN-1 promoted the sensitivity to chemotherapeutic drugs and attenuated metastasis and the invasion ability of A549/DDP (a MDR cell line of NSCLC) cells [36]. The studies mentioned above suggest that CNTN-1 may contribute to the EMT process and resulting chemoresistance in A549/DDP cells as a mediator.

To test the hypothesis, A549/DDP cells and xenograft mouse models established with the corresponding cells were utilized and the data demonstrated that the EMT phenotype and malignant progression of A549/DDP cells was regulated by CNTN-1 via activation of the PI3K/Akt signaling pathway. CNTN-1 may be a potential therapeutic target to reverse the chemoresistance and malignant progression in cisplatin-resistant lung adenocarcinoma.

\section{Materials and Methods}

Ethics statement

All experiments were approved by the Experimental Animal Ethics Committee of Xinqiao Hospital affiliated with the Third Military Medical University [SYXK (YU) 2012-0011].

Cell lines and culture conditions

The human lung adenocarcinoma cell line (A549) was purchased from the Institute of Biochemistry and Biology, Chinese Academy of Sciences (Shanghai, China) and cultured in RPMI-1640 medium containing $10 \%$ fetal bovine serum (FBS, Gibco, USA) under standard conditions $\left(37^{\circ} \mathrm{C}, 20 \% \mathrm{O}_{2}\right.$, and $\left.5 \% \mathrm{CO}_{2}\right)$. The 


\section{Cellular Physiology Cell Physiol Biochem 2017;43:465-480 \\ \begin{tabular}{ll|l} 
and Biochemistry & $\begin{array}{l}\text { DOI: 10.1159/000480473 } \\
\text { Published online: September 19, } 2017\end{array}$ & $\begin{array}{l}\text { C) } 2017 \text { The Author(s). Published by S. Karger AG, Base } \\
\text { www.karger.com/cpb }\end{array}$ \\
\hline
\end{tabular} \\ Zhang et al.: CNTN-1 Enhances Chemoresistance through Inducing EMT in Human Lung Adenocarcinoma}

cisplatin-resistant cell line (A549/DDP) was established and verified as described in our previous studies [36-37].

\section{Cell transfection}

The recombinant lentiviral vectors LV5-CNTN-1 and LV3-CNTN-1 (GenePharma, Shanghai, China) were used to overexpress CNTN-1 in A549 cells (A549-CNTN-1, the full sequence of the recombinant lentiviral vector LV5-CNTN-1 was obtained from https://www.ncbi.nlm.nih.gov/nuccore/NM_001256063.1) and silence CNTN-1 in A549/DDP cells (A549/DDP-shCNTN-1, the shRNA human CNTN-1-targeting sequence was 5'-ACAGAAAGATGCTGGAATATA-3'), respectively. Cells transfected with negative vectors (A549CNTN-1-NC and A549/DDP-shCNTN-1-NC) were used as controls. According to the operation manual, the transfected cells were selected via puromycin and cultured for future use.

\section{Cell morphology observation}

Cell morphology was first observed using a light microscopy (Olympus BX51, Japan). Additionally, cancer cells were viewed under a fluorescence microscope (Olympus IX71, Japan) after staining with Alexa Fluor 488 Phalloidin (Invitrogen) according to the manufacturer's instructions.

Anoikis resistance assay

Briefly, after $5 \times 10^{5}$ cells were seeded in a 6 -well plate coated with $12 \mathrm{mg} / \mathrm{mL}$ poly-2-hydroxyethyl methacrylate (poly-HEMA, Sigma) to prevent cell attachment and suspension-cultured for $48 \mathrm{hrs,} \mathrm{the} \mathrm{cell}$ clones suspended in the medium were captured under a light microscope (Olympus BX51, Japan) and harvested to examine the apoptotic ratio of cells by flow cytometry using the annexin V-FITC/PI staining method (Beyotime, China).

Cell apoptosis analysis

After cells were seeded in petri dishes (10-cm diameter, $3 \times 10^{4}$ cells per dish) and grown to $70-80 \%$ confluence, the cells were incubated with $2 \mu \mathrm{g} / \mathrm{mL}$ cisplatin for $48 \mathrm{hrs}$ and collected. Then, flow cytometry assay was performed to detect apoptotic cells using the annexin V-FITC/PI staining method (Beyotime, China).

\section{In vitro drug sensitivity assay}

Briefly, after cells were incubated with different concentrations of cisplatin $(10,5,2.5,1.25,0.625$, and $0 \mathrm{ug} / \mathrm{mL}$ ) for $48 \mathrm{hrs}, 100 \mu \mathrm{l}$ fresh culture medium and $10 \mu \mathrm{l}$ Cell Counting Kit-8 (CCK-8) solution (Beyotime, China) were added to each well and incubated for $1 \mathrm{hr}$. Then, the absorbance value at the wavelength of 450 $\mathrm{nm}$ was measured. Cells incubated without cisplatin were treated as negative controls. The $50 \%$ inhibitory concentration $\left(\mathrm{IC}_{50}\right.$ ) was calculated using GraphPad Prism 5.0 software.

\section{Migration and invasion assay}

The migration ability of cancer cells was evaluated by a wound-healing assay. Briefly, after cells were seeded in a 6 -well plate $\left(5 \times 10^{5}\right.$ cells per well) and cultured overnight, the confluent cell monolayer was sequentially scratched in a straight line with a $200-\mu$ l pipette tip, washed with sterile PBS and cultured in fresh medium for $20 \mathrm{hrs}$. Migrated cells were photographed at $0 \mathrm{hr}$ and $20 \mathrm{hrs}$ under a light microscope (Olympus BX51, Japan). The cell metastasis ability in each group was calculated using Image-Pro Plus software (Version 5.1, Media Cybernetics, Inc.). The cell invasion ability was evaluated using modified Boyden chambers with filter inserts (pore size of $8 \mu \mathrm{m}$, Corning Inc., Life Science) according to our previous method [36]. Invasive cells were observed under a light microscope (Olympus BX51, Japan), and calculated using Image-Pro Plus software (Version 5.1, Media Cybernetics, Inc.).

\section{RNA isolation and real-time PCR analysis}

After the total RNA of cancer cells was extracted using TRIzol reagent (Invitrogen, USA) according to the manufacturer's instructions, first-strand cDNA was synthesized from total RNA (1 ug) using a First Strand cDNA Synthesis Kit (Roche). Then, real-time PCR was performed on a reaction system containing cDNA, SYBR Green Mix (TOYOBO), and primers (Table 1). Glyceraldehyde-3-phosphate dehydrogenase $(\mathrm{GAPDH})$ was used as an internal control. The relative expression of target genes was expressed as $2^{-\Delta \Delta C \mathrm{Ct}}$. 
Cell Physiol Biochem 2017;43:465-480

Zhang et al.: CNTN-1 Enhances Chemoresistance through Inducing EMT in Human Lung Adenocarcinoma

Table 1. Primers of target genes

\begin{tabular}{lcll}
\hline Gene & Accession number & Forward $\left(5^{\prime}-3^{\prime}\right)$ & Reverse $\left(5^{\prime}-3^{\prime}\right)$ \\
\hline GAPDH & NM_001256799.2 & CAGCCTCAAGATCATCAGCA & TGTGGTCATGAGTCCTTCCA \\
CNTN-1 & NM_001256063.1 & GCCCATGACAAAGAAGAAGC & CGACATGATCCCAGGTGATT \\
E-cadherin & NM_001317184.1 & GAAGTGTCCGAGGACTTTGG & CAGTGTCTCTCCAAATCCTAGA \\
N-cadherin & NM_001308176.1 & GAGTCCACTGAGTACCGGAGAC & TGTAGGTGGCAATCTCAATGTC \\
vimentin & NM_003380.3 & AAAGTGTGGCTGCCAAGAAC & AGCCTCAGAGAGGTCAGCAA \\
\hline
\end{tabular}

Table 2. Primary and secondary antibodies used in this study (WB: Western blotting, IHC: Immunohistochemistry)

\begin{tabular}{lccc}
\hline Antibodies & Purchase information & Host & Application and dilution \\
\hline Anti- $\beta$-actin antibody & Proteintech & Mouse & $1: 1000$ for WB \\
Anti-CNTN-1 antibody & Proteintech & Rabbit & $1: 1000$ for WB and 1:400 for IHC \\
Anti-E-cadherin antibody & Cell Signaling Technology & Rabbit & $1: 1000$ for WB and 1:400 for IHC \\
Anti-N-cadherin antibody & Abcam & Rabbit & $1: 1000$ for WB and 1:400 for IHC \\
Anti-vimentin antibody & Cell Signaling Technology & Rabbit & $1: 1000$ for WB and 1:400 for IHC \\
Anti-Akt antibody & Cell Signaling Technology & Rabbit & $1: 1000$ for WB \\
Anti-p-Akt antibody & Cell Signaling Technology & Rabbit & $1: 1000$ for WB \\
Goat anti-mouse IgG & ZSGB-Bio, China & Goat & $1: 2000$ for WB and 1:200 for IHC \\
Goat anti-rabbit IgG & ZSGB-Bio, China & Goat & $1: 2000$ for WB and 1:200 for IHC \\
\hline
\end{tabular}

Western blot analysis

After the total protein was extracted from cancer cells using RIPA lysis solution (Beyotime, China), protein expression was analyzed by Western blotting assay as described previously [36]. The primary antibodies and secondary antibodies used in this experiment are listed in Table 2. Protein bands were visualized using a SuperSignal West Pico Trial Kit (Thermo) and analyzed using Image J software (National Institutes of Health, USA).

Xenograft tumorigenicity experiment

Healthy SCID mice (Four to five-week-old female, $\mathrm{n}=20$ ) were purchased from the Animal Laboratory of Xinqiao Hospital and housed in a climate-control SPF (Specific Pathogen Free) facility. The mice were divided into two groups that were subcutaneously inoculated with A549/DDP-shCNTN-1 cells and A549/ DDP-shCNTN-1-NC cells into the right flank $\left(100 \mu \mathrm{L}, 1 \times 10^{6}\right.$ cells per animal), respectively. Tumors were monitored on the day of tumor formation and measured every three days for a total of 48 days. Tumor volume $\left(\mathrm{mm}^{3}\right)$ was calculated according to the formula $a \times b^{2} / 2$ (a=largest diameter; $b=$ smallest diameter) [38]. As previously described [16], when the tumor volume reached $150 \mathrm{~mm}^{3}$, one subgroup of nude mice in each group was injected with a cisplatin solution (cisplatin concentration: $10 \mathrm{mg}$ per $2 \mathrm{~mL}$ in normal saline (NS); injection dosage: $0.2 \mathrm{mg}$ cisplatin per $10 \mathrm{~g}$ animal weight $(20 \mathrm{mg} / \mathrm{kg})$ ) via intraperitoneal injection every three days, while the other subgroup of mice was used as controls and injected with NS. After 48 days, saline-treated xenograft tumors (A549/DDP-shCNTN-1-NC and A549/DDP-shCNTN-1) were isolated to detect protein expression of CNTN-1 and EMT biomarkers by Western blot and immunohistochemistry, respectively. Meanwhile, the lung and liver tissues were separated to observe tumor metastasis in vivo by HE staining.

Hematoxylin and eosin (HE) staining and immunohistochemistry

Tissue samples including xenograft tumors, lung tissues, and liver tissues were sequentially fixed with $4 \%$ paraformaldehyde for $24 \mathrm{hrs}$, embedded in paraffin, and sectioned. Then, HE staining and immunostaining 


\section{Cellular Physiology Cell Physiol Biochem 2017;43:465-480 \begin{tabular}{l|l|l} 
and Biochemistry Published online: September 19, 2017 & $\begin{array}{l}\text { C) } 2017 \text { The Author(s). Published by S. Karger AG, Base } \\
\text { www.karger.com/cpb }\end{array}$ \\
\hline
\end{tabular} \\ Zhang et al.: CNTN-1 Enhances Chemoresistance through Inducing EMT in Human Lung Adenocarcinoma}

were performed on the 4- $\mu$ m-thick sections of xenograft tumors as previously described [36]. The primary and secondary antibodies used for immunohistochemistry are shown in Table 2. Additionally, HE staining was performed on the 4- $\mu$ m-thick sections of liver and lung tissues to simply observe the metastasis of the xenografted tumors in vivo. All sections were observed under a light microscope (Olympus BX51, Japan).

\section{Statistical analysis}

All numerical data in this study were presented as the mean \pm SD and analyzed using SPSS 13.0 software. After a homogeneity test for variance, the significant difference between two groups was analyzed using an independent-samples t test, whereas the significant difference between multiple groups was analyzed by one-way analysis of variance (ANOVA) followed by LSD post hoc test. A p-value of less than 0.05 was regarded as statistically significant.

\section{Results}

Cisplatin-resistant lung adenocarcinoma cells displayed an EMT phenotype

Consistent with our previous report [36], A549/DDP cells exhibited more resistance to cisplatin than A549 cells (Fig. 1A), verified by the apoptosis analysis, which showed that A549/DDP cells displayed a lower percentage of apoptotic cells than A549 cells when exposed to cisplatin (Fig. 1B). To evaluate the association of EMT development with cisplatin resistance, EMT-related cellular morphological changes and expression of EMTrelated markers (E-cadherin, $\mathrm{N}$-cadherin and vimentin) were compared between A549 cells and A549/DDP cells. Interestingly, A549/DDP cells displayed an elongated and irregular fibroblastic morphology with growth separately from one another, whereas A549 cells exhibited an epithelial morphology characterized by a round shape and growth in clusters (Fig. 1C), verified by the cytoskeleton F-actin staining (Fig. 1D). Compared with that of A549 cells, both the expression of $\mathrm{N}$-cadherin and vimentin (mesenchymal markers) was upregulated, while the expression of E-cadherin (epithelial marker) was downregulated in A549/DDP cells both at the mRNA and protein levels (Fig. 1E-F). These results indicate that cisplatin-resistant lung adenocarcinoma cells acquire an EMT phenotype.

Additionally, the association of the EMT phenotype with malignant progression was also analyzed in A549/DDP and A549 cells. The wound-healing assay and transwell invasion assay showed that the migration and invasion of A549/DDP cells was significantly greater than that of A549 cells (Fig. 2A-B). Moreover, the anoikis resistance assay showed that A549/DDP cells formed larger cellular aggregates than A549 cells, which mainly were found as individual cells and smaller cellular aggregates (Fig. 2C). Flow cytometry analysis of these suspended cells demonstrated that A549 cells had a higher proportion of anoikis than A549/DDP cells (Fig. 2D). Furthermore, the expression of pluripotent markers (CD44, OCT-4 and Nanog) was higher in A549/DDP cells than in A549 cells (Fig. 2E). Collectively, these findings suggest that EMT development in cisplatin-resistant lung adenocarcinoma cells aggravates tumor malignant behaviors.

CNTN-1 expression positively correlated with the EMT phenotype, cisplatin resistance, and tumor malignant progression in lung adenocarcinoma cells

Our previous studies found that CNTN-1 was significantly upregulated in A549/DDP cells compared with that of A549 cells [36]. To investigate whether the EMT phenotype was correlated with CNTN-1, CNTN-1 was successfully overexpressed in A549 cells (A549CNTN-1, Fig. 3A-B) and silenced in A549/DDP cells (A549/DDP-shCNTN-1, Fig. 3C-D) both at the gene and protein levels. Then, the expression of EMT-related markers was detected, and the data revealed that A549-CNTN-1 cells displayed an EMT phenotype, characterized by upregulated expression of mescenchymal markers (N-cadherin and vimentin) and downregulated expression of the epithelial marker (E-cadherin) (Fig. 3E-F), whereas A549/ DDP-shCNTN-1 cells had a significantly attenuated EMT phenotype, characterized by the opposite trend in EMT-related marker expression (Fig. 3G-H). These molecular changes 


\section{Cellular Physiology \\ Cell Physiol Biochem 2017;43:465-480 \begin{tabular}{ll|l} 
and Biochemistry & DOI: 10.1159/000480473 & $\begin{array}{l}\text { P 2017 The Author(s). Published by S. Karger AG, Basel } \\
\text { www.karger.com/cpb }\end{array}$ \\
\cline { 2 - 3 }
\end{tabular} \\ Zhang et al.: CNTN-1 Enhances Chemoresistance through Inducing EMT in Human Lung Adenocarcinoma}

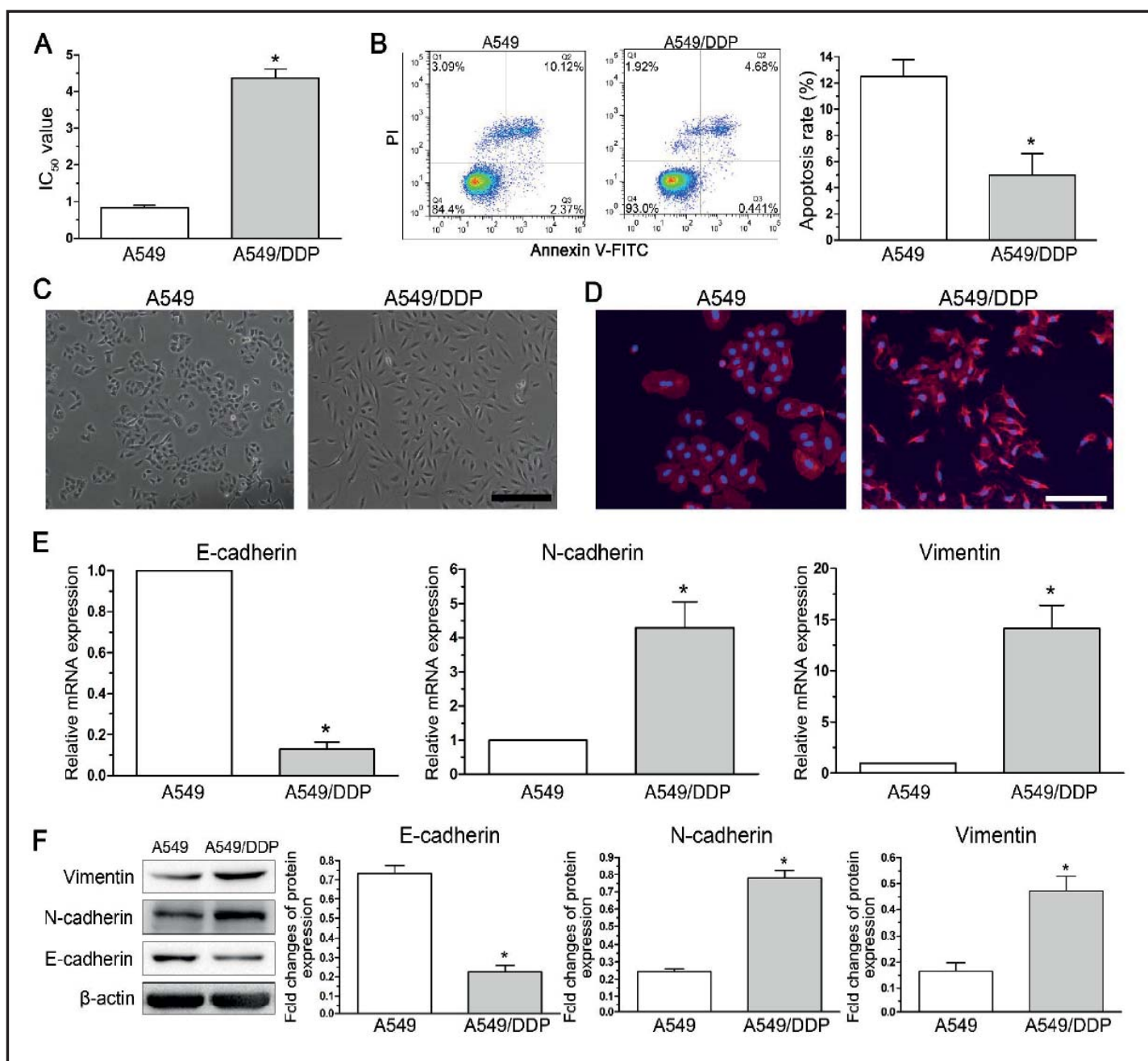

Fig. 1. Cisplatin-resistant lung adenocarcinoma cells displayed an EMT phenotype. $A: \mathrm{IC}_{50}$ of cisplatin in A549 cells and A549/DDP cells. B: Apoptosis assay by flow cytometry. The apoptosis rate of A549 cells and A549/DDP cells was evaluated using the annexin V-FITC/PI staining method after incubation with $2 \mu \mathrm{g} /$ $\mathrm{mL}$ cisplatin for $48 \mathrm{hrs}$. C and D: Cellular morphology observation (Magnification: $100 \times$, bar $=200 \mu \mathrm{m}$ ) and F-actin staining assay (Magnification: 200x, bar $=100 \mu \mathrm{m}$ ) in A549 cells and A549/DDP cells. E and F: Real-time PCR analysis and Western blotting analysis of EMT-related markers (E-cadherin, N-cadherin, and vimentin), respectively. Data are expressed as the mean \pm SD $(n=3) . *$ : significant difference between two groups $(\mathrm{p}<0.05)$.

were verified by EMT-associated morphological changes, characterized by an elongated and irregular mesenchymal phenotype in A549-CNTN-1 cells in contrast to an epithelial phenotype in A549-shCNTN-1 cells (Fig. 3I). Moreover, CNTN-1 overexpression significantly decreased cisplatin sensitivity and apoptosis (A549-CNTN-1 vs A549-CNTN-1-NC), while CNTN-1 silencing significantly increased cisplatin sensitivity and apoptosis (A549/DDPshCNTN-1 vs A549/DDP-shCNTN-1-NC, Fig. 3J-K).

Additionally, CNTN-1 overexpression induced the formation of large cell aggregates (Fig. 4A), decreased the proportion of anoikis (Fig. 4B), and promoted cell migration (Fig. 4C) and invasion (Fig. 4D) (A549-CNTN-1 vs. A549-CNTN-1-NC), whereas CNTN-1 silencing inhibited cell aggregate formation (Fig. 4A), increased the proportion of anoikis (Fig. 4B), and inhibited cell migration (Fig. 4C) and invasion (Fig. 4D) (A549/DDP-shCNTN-1 vs. A549/ DDP-shCNTN-1-NC), strongly suggesting that the EMT process is correlated with cisplatin resistance and malignant behavior in lung adenocarcinoma cells via CNTN-1. 


\section{Cellular Physiology \\ Cell Physiol Biochem 2017;43:465-480 \\ \begin{tabular}{ll|l} 
and Biochemistry Published online: September 19, 2017 & $\begin{array}{l}\text { (c) } 2017 \text { The Author(s). Published by S. Karger AG, Base } \\
\text { www.karger.com/cpb }\end{array}$ \\
\hline
\end{tabular} \\ Zhang et al.: CNTN-1 Enhances Chemoresistance through Inducing EMT in Human Lung Adenocarcinoma}

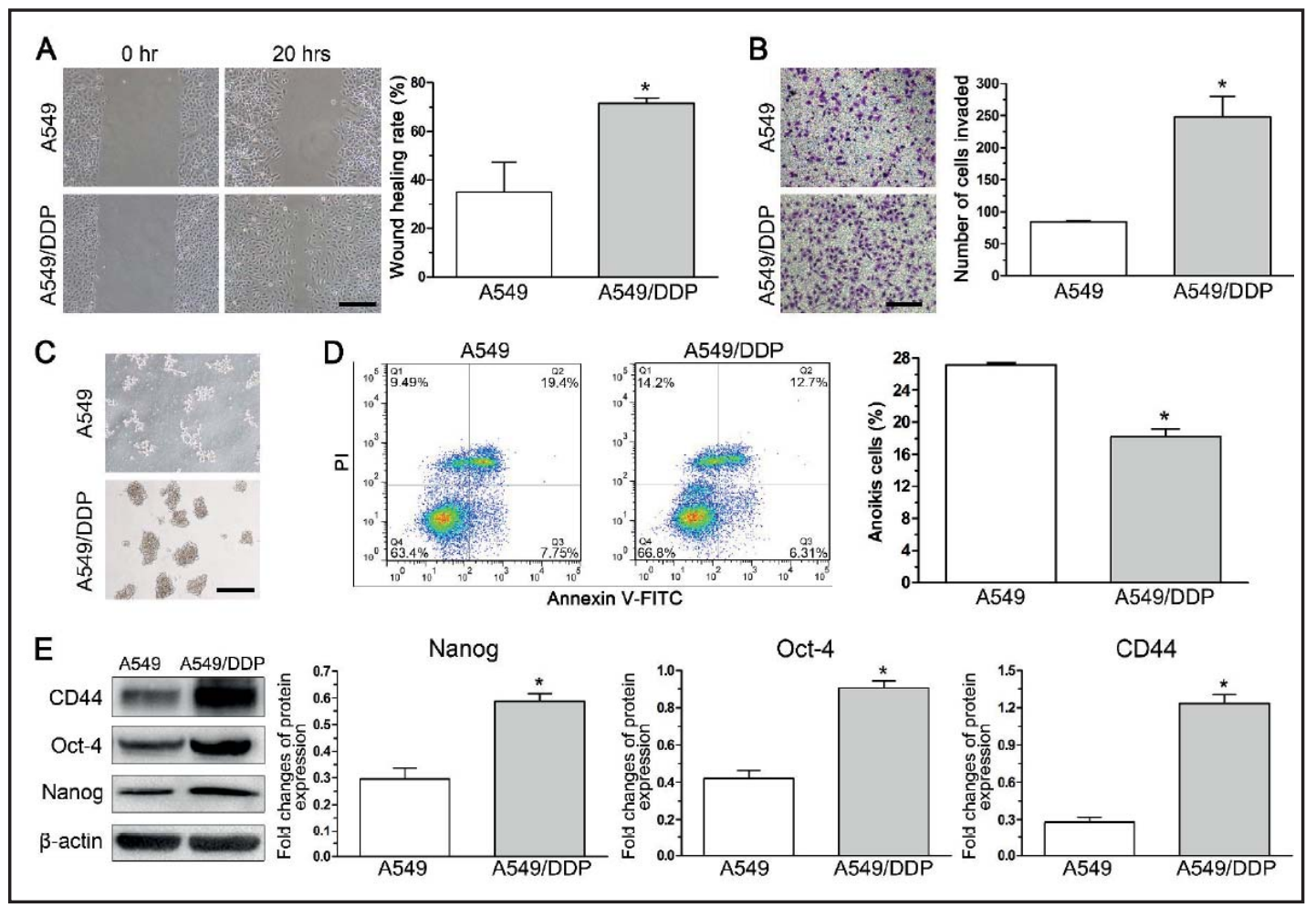

Fig. 2. Cisplatin-resistant lung adenocarcinoma cells with an EMT phenotype exhibit promoted tumor malignant behaviors. A: Cell migration ability assessed by wound-healing assay (Magnification: 100×, bar=200 $\mu \mathrm{m})$. B: Cell invasion ability assessed by transwell invasion assay (Magnification: $100 \times$, bar=200 $\mu \mathrm{m}$ ). C: Anoikis morphology observation after A549 cells and A549/DDP cells were cultured in poly-HEMA-coated plates for 48 hrs (Magnification: 100x, bar=200 $\mu \mathrm{m}$ ). D: Anoikis rate evaluated by flow cytometry. E: Western blotting analysis of pluripotent markers (CD44, OCT-4 and Nanog). Data are expressed as the mean \pm SD $(\mathrm{n}=3)$ *: significant difference between two groups $(\mathrm{p}<0.05)$.

CNTN-1 facilitated the EMT process and resulting cisplatin resistance via activating the PI3K/Akt signaling pathway

The PI3K/Akt pathway is not only a vital signal transduction pathway that regulates EMT development [39-40] but also an efficient target to promote drug sensitivity in some cancer cells [41]. To explore the mechanisms of CNTN-1 involvement in the EMT phenotype, cisplatin resistance, and malignant behavior in lung adenocarcinoma cells, PI3K/Akt activity was analyzed and the results demonstrated that the PI3K/Akt pathway was more activated in A549/DDP cells than in A549 cells, which was coincident with CNTN-1 expression (Fig. 5A). Moreover, p-Akt was significantly upregulated in A549-CNTN-1 cells but downregulated in A549/DDP-shCNTN-1 cells, indicating that the PI3K/Akt activity was regulated by CNTN1 (Fig. 5B).

Because an inhibitor of CNTN-1 is not available presently, LY294002, an inhibitor of PI3K/Akt pathway, was used to verify the association of PI3K/Akt activity with CNTN-1, the EMT phenotype, and tumor malignant behaviors of cisplatin-resistant lung adenocarcinoma cells. As shown Fig. 5C, inhibition of the PI3K/Akt pathway had no influence on CNTN-1 expression, confirming that $\mathrm{CNTN}-1$ is an upstream molecule regulating the PI3K/Akt signaling pathway. Additionally, when the PI3K/Akt pathway was inhibited, the mesenchymallike cellular morphology was reversed (Fig. 5D), and epithelial marker (E-cadherin) expression was significantly upregulated, whereas the expression of mesenchymal markers (N-cadherin and vimentin) was significantly downregulated (A549/DDP-LY294002 vs. A549/DDP) (Fig. 5E). Moreover, inhibitor LY294002 increased the sensitivity of A549/DDP cells to cisplatin (Fig. 5F) and attenuated cell metastasis and invasion (Fig. 5G-H). These 


\section{Cellular Physiology Cell Physiol Biochem 2017;43:465-480 \begin{tabular}{c|c|c|} 
DOI: 10.1159/000480473 & O 2017 The Author(s). Published by S. Karger AG, Basel \\
and Biochemistryarger.com/cpb
\end{tabular} \\ Zhang et al.: CNTN-1 Enhances Chemoresistance through Inducing EMT in Human Lung Adenocarcinoma}

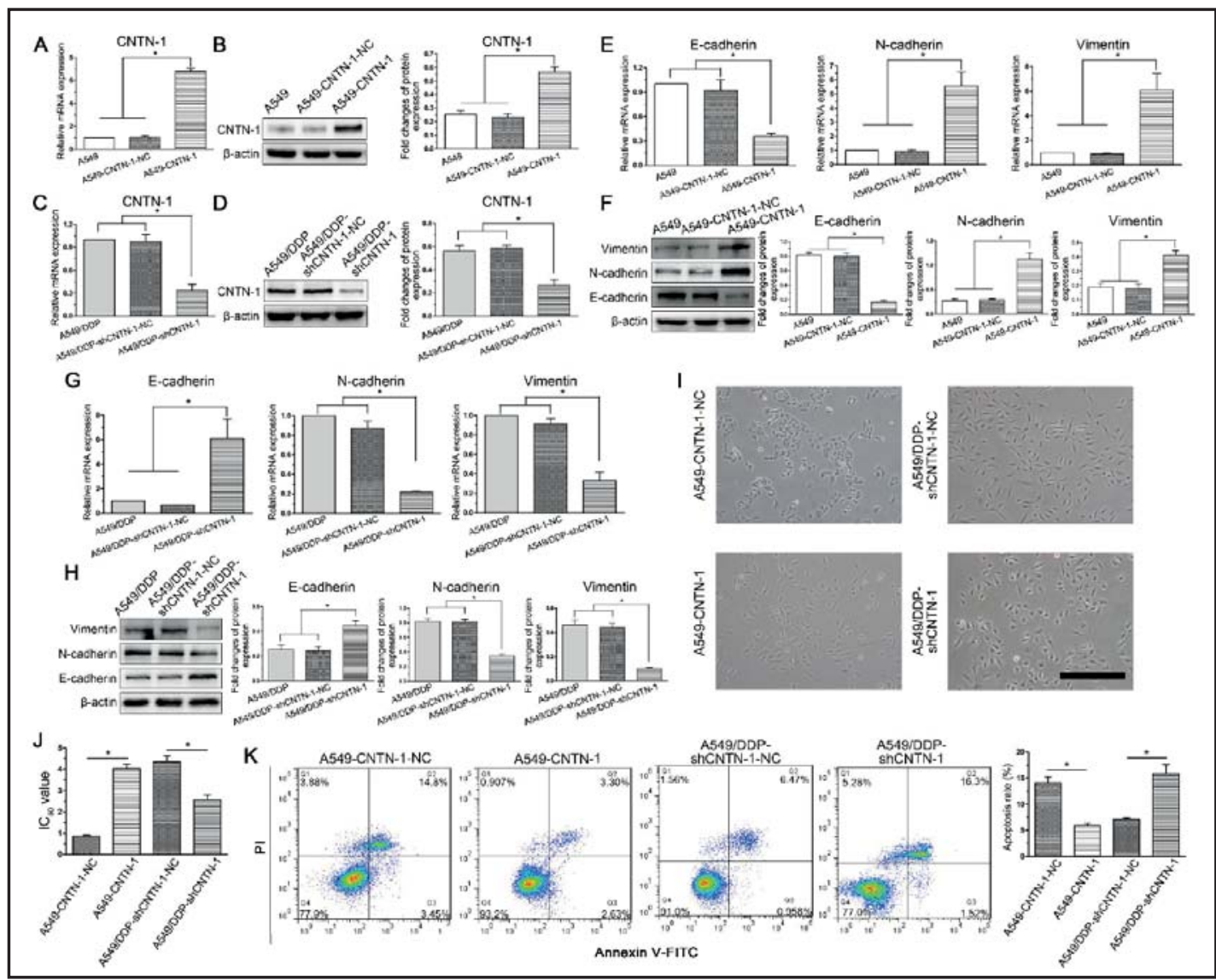

Fig. 3. Alteration of contactin-1 (CNTN-1) expression correlated with EMT phenotype and cisplatin resistance in lung adenocarcinoma cells. A-D: Verification of CNTN-1 overexpression in A549 cells and CNTN1 knockdown in A549/DDP cells by real-time PCR (A and C) and Western blotting (B and D) assays, respectively. E-H: Real-time PCR (E and G) and Western blotting (F and H) analysis of expression of EMT-related markers (E-cadherin, N-cadherin, and vimentin) after CNTN-1 was overexpressed in A549 cells and silenced in A549/DDP cells, respectively. I: Cell morphological observation after CNTN-1 was overexpressed (A549CNTN-1-NC vs A549-CNTN-1) in A549 cells and silenced in A549/DDP cells (A549/DDP-shCNTN-1-NC vs A549/DDP-shCNTN-1, Magnification: $100 \times$, bar $=200 \mu \mathrm{m}$ ). J: IC $_{50}$ of cisplatin after CNTN-1 was overexpressed in A549 cells and silenced in A549/DDP cells, respectively. K: Apoptosis assay by flow cytometry in A549 cells with CNTN-1 overexpression and A549/DDP cells with CNTN-1 knockdown. Cell apoptosis was evaluated using the annexin V-FITC/PI staining method after incubation with $2 \mu \mathrm{g} / \mathrm{mL}$ cisplatin for $48 \mathrm{hrs}$. Data are expressed as the mean \pm SD $(n=3)$. *: significant difference between two groups $(\mathrm{p}<0.05)$.

findings suggest that CNTN-1 participates in the EMT process which leads to malignant progression in lung adenocarcinoma cells via activating the PI3K/Akt pathway.

Knockdown of CNTN-1 reversed cisplatin resistance and the EMT phenotype of A549/DDP cells in vivo

To investigate the potential of CNTN-1 to reverse the EMT phenotype and cisplatin resistance of lung adenocarcinoma cells in clinical practice, a xenograft mouse model was established. Although no significant difference in the tumor volume was found between A549/DDP-shCNTN-1 and A549/DDP-shCNTN-1-NC before cisplatin supplementation (on day 30), further growth of the tumors developed with A549/DDP-shCNTN-1 was significantly prevented after the next 3 weeks cisplatin injection (A549/DDP-shCNTN-1 vs. A549/DDPshCNTN-1-NC) (Fig. 6A-B). In addition, the final tumor weight of the A549/DDP-shCNTN-1 


\section{Cellular Physiology \\ Cell Physiol Biochem 2017;43:465-480

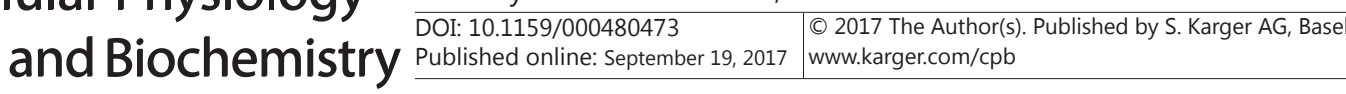 \\ Zhang et al.: CNTN-1 Enhances Chemoresistance through Inducing EMT in Human Lung Adenocarcinoma}

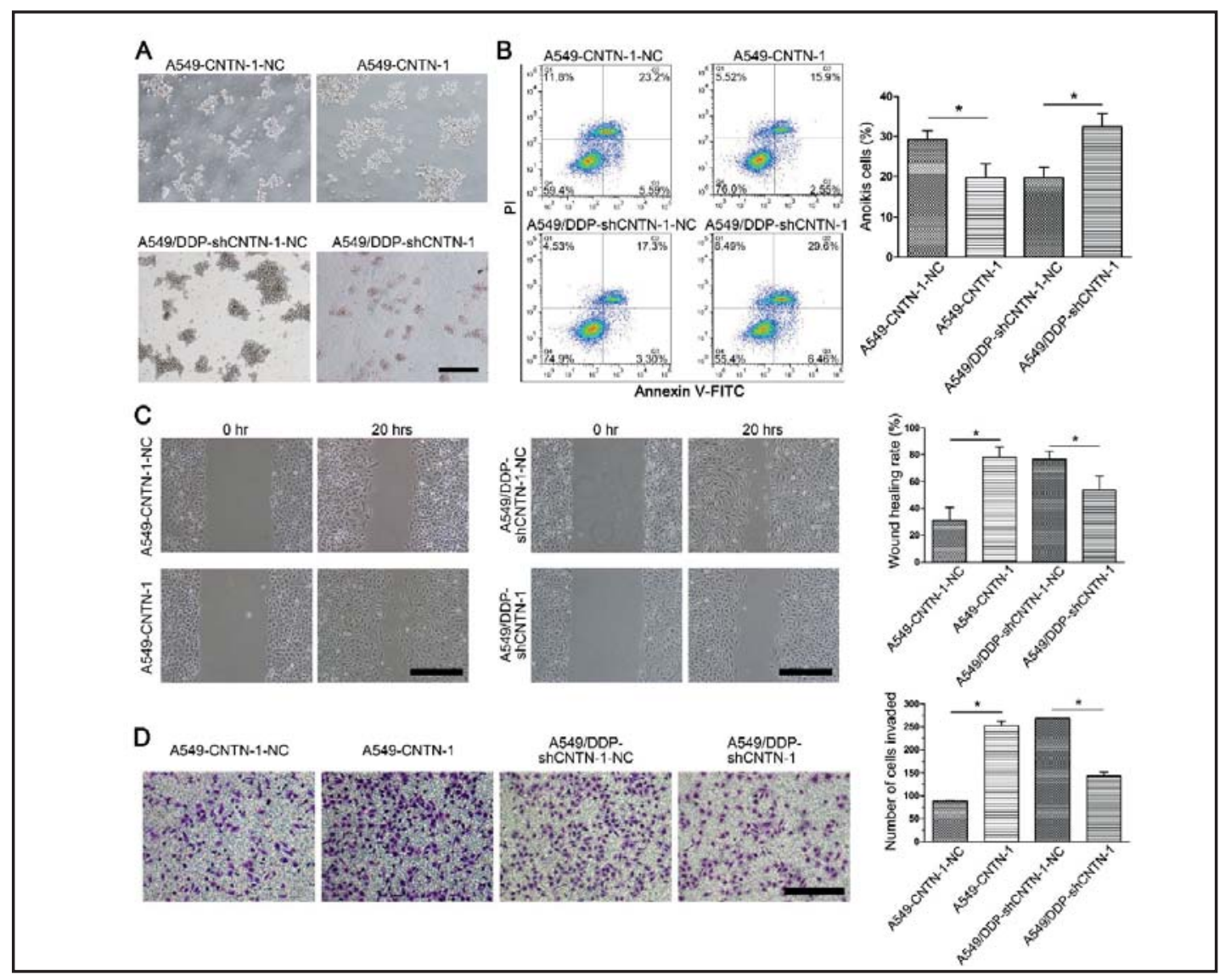

Fig. 4. CNTN-1 expression positively correlated with tumor malignant progression in lung adenocarcinoma cells. A: Anoikis morphology observation after CNTN-1 was overexpressed in A549 cells and silenced in A549/DDP cells (Magnification: 100x, bar=200 $\mu \mathrm{m}$ ). B: Anoikis rate examined by flow cytometry after CNTN-1 was overexpressed in A549 cells and silenced in A549/DDP cells. C and D: Cell migration ability assessed by wound-healing assay and cell invasion ability assessed by transwell invasion assay after CNTN1 was overexpressed in A549 cells and silenced in A549/DDP cells, respectively (Magnification: 100×, bar = $200 \mu \mathrm{m})$. Data are expressed as the mean \pm SD $(n=3)$. * significant difference between two groups $(\mathrm{p}<0.05)$.

subgroup treated with cisplatin was significantly lower than that of the other subgroups (Fig. 6C), indicating that CNTN-1 contributed to cisplatin resistance rather than the tumor growth of lung adenocarcinoma cells.

Moreover, consistent with the results of cell models, expression of both CNTN-1 and p-Akt in tumors developed with A549/DDP-shCNTN-1-saline cells was lower than in tumors developed with A549/DDP-shCNTN-1-NC-saline cells (Fig. 6D). Furthermore, in tumors developed with A549/DDP-shCNTN-1-saline cells, mesenchymal marker (N-cadherin) expression decreased and epithelial marker (E-cadherin) expression increased compared with that of the tumors developed with A549/DDP-shCNTN-1-NC-saline cells (Fig. 6E-F). Additionally, HE staining seemed to show a more epithelial-like morphology in the tumors developed with A549/DDP-shCNTN-1-saline cells compared with that of the tumors developed with A549/DDP-shCNTN-1-NC-saline cells (Fig. 6G). These results further confirm that CNTN-1 contributes to EMT progression in cisplatin-resistant lung adenocarcinoma cells. Additionally, consistent with the findings in vitro (Fig. 4D), HE staining showed that xenograft tumors developed with A549/DDP-shCNTN-1-NC cells likely exhibited more obvious metastasis potency in liver and lung tissue than those developed with of A549/DDPshCNTN-1 cells (Fig. 7). 


\section{Cellular Physiology Cell Physiol Biochem 2017;43:465-480 \begin{tabular}{l|l|l|l|l}
\hline DOI: 10.1159/000480473 & ( 2017 The Author(s). Published by S. Karger AG, Basel
\end{tabular}

A
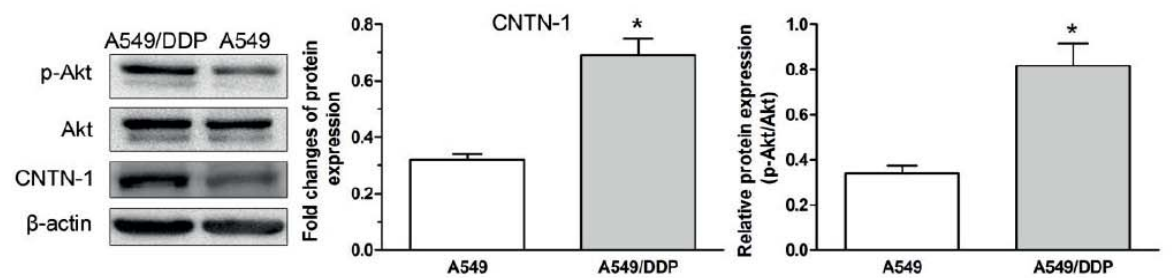

B
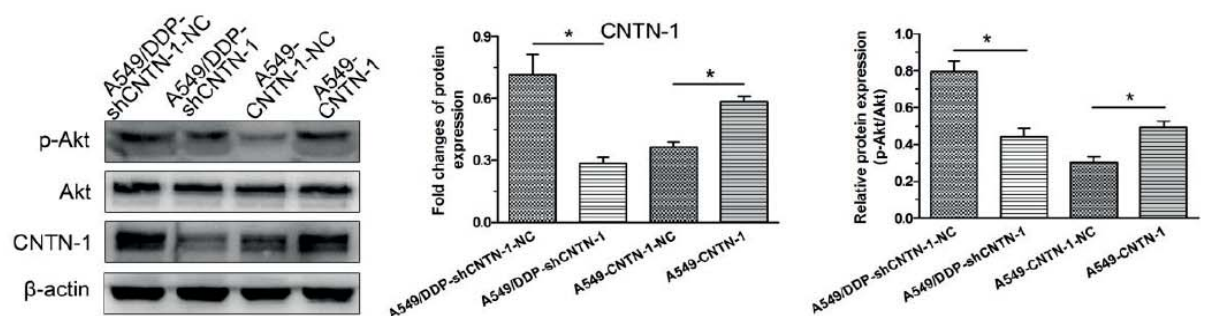

C
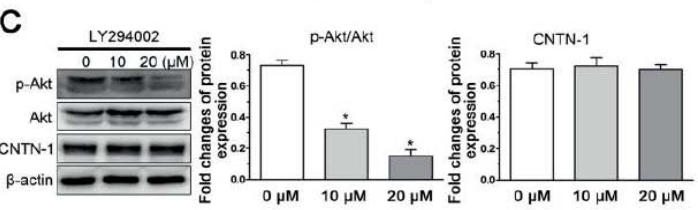

D $0 \mu \mathrm{M}$
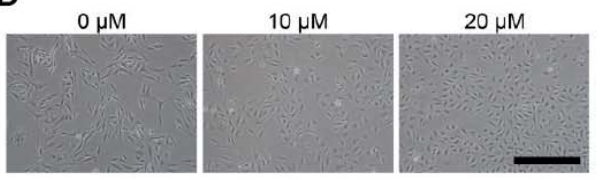

$\mathrm{E}$
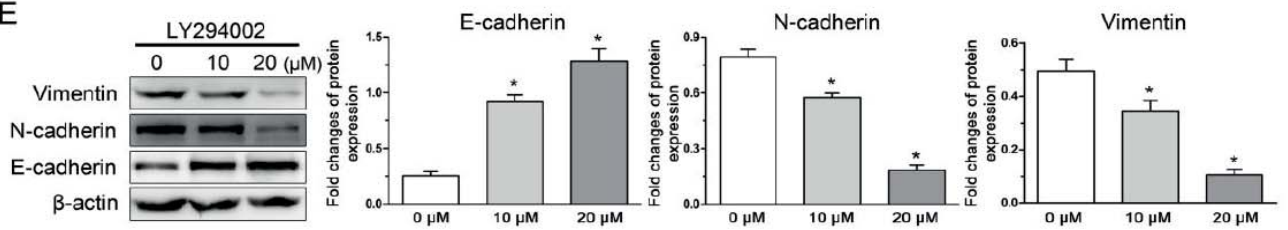

$F$

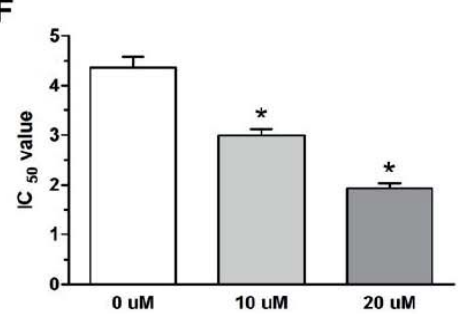

G $\quad 0 \mathrm{hr}$
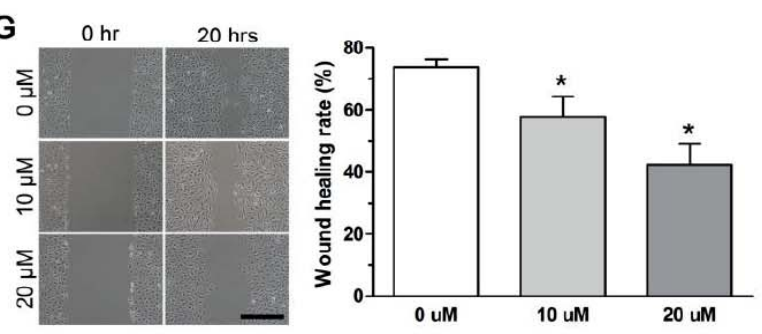

$\mathrm{H}$
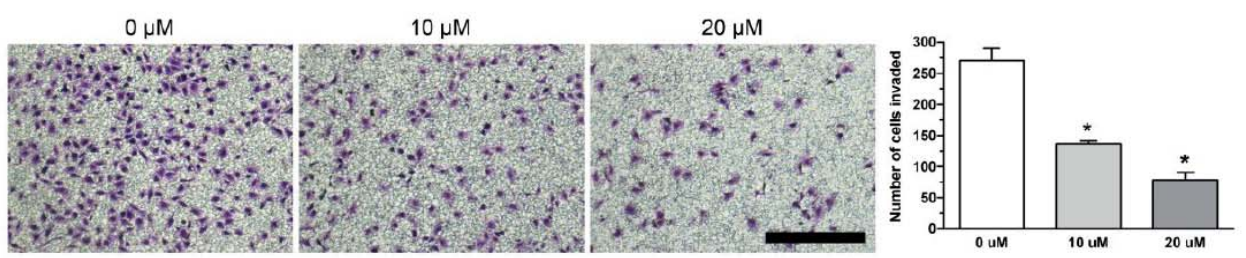

Fig. 5. Inhibition of the PI3K/Akt signaling pathway partly reversed the effects of CNTN-1 upregulation on the EMT phenotype, cisplatin resistance, and malignant progression in cisplatin-resistant lung adenocarcinoma cells. A: Western blotting analysis of p-Akt and CNTN-1 expression in A549 cells and A549/DDP cells. B: Changes in p-Akt expression after CNTN-1 was overexpressed in A549 cells and silenced in A549/DDP cells. C: Expression of p-Akt and CNTN-1 in A549/DDP cells after incubation with 10 and $20 \mu \mathrm{M}$ inhibitor LY294002. D: Cell morphological changes of A549/DDP cells treated with inhibitor LY294002 (magnification: $100 \times$, bar $=200 \mu \mathrm{m}$ ). E: Western blotting analysis of EMT-related markers (E-cadherin, N-cadherin, and vimentin) in A549/DDP cells treated with inhibitor LY294002. F: IC $_{50}$ of cisplatin in A549/DDP cells treated with inhibitor LY294002. G and H: Cell metastasis and cell invasion in A549/DDP cells treated with inhibitor LY294002, respectively (magnification: $100 \times$, bar $=200 \mu \mathrm{m}$ ). Data are expressed as the mean \pm SD $(\mathrm{n}=3)$. \#: significant difference between two groups $(\mathrm{p}<0.05) .{ }^{*}$ : significant difference when compared with the control group (A549/DDP cells treated with $0 \mu \mathrm{M}$ LY294002). 


\section{Cellular Physiology \\ Cell Physiol Biochem 2017;43:465-480 \\ \begin{tabular}{ll|l} 
and Biochemistry & Published online: September 19, 2017 & $\begin{array}{l}\text { ( ) } 2017 \text { The Author(s). Published by S. Karger AG, Basel } \\
\text { www.karger.com/cpb }\end{array}$ \\
\hline
\end{tabular} \\ Zhang et al.: CNTN-1 Enhances Chemoresistance through Inducing EMT in Human Lung}

Adenocarcinoma

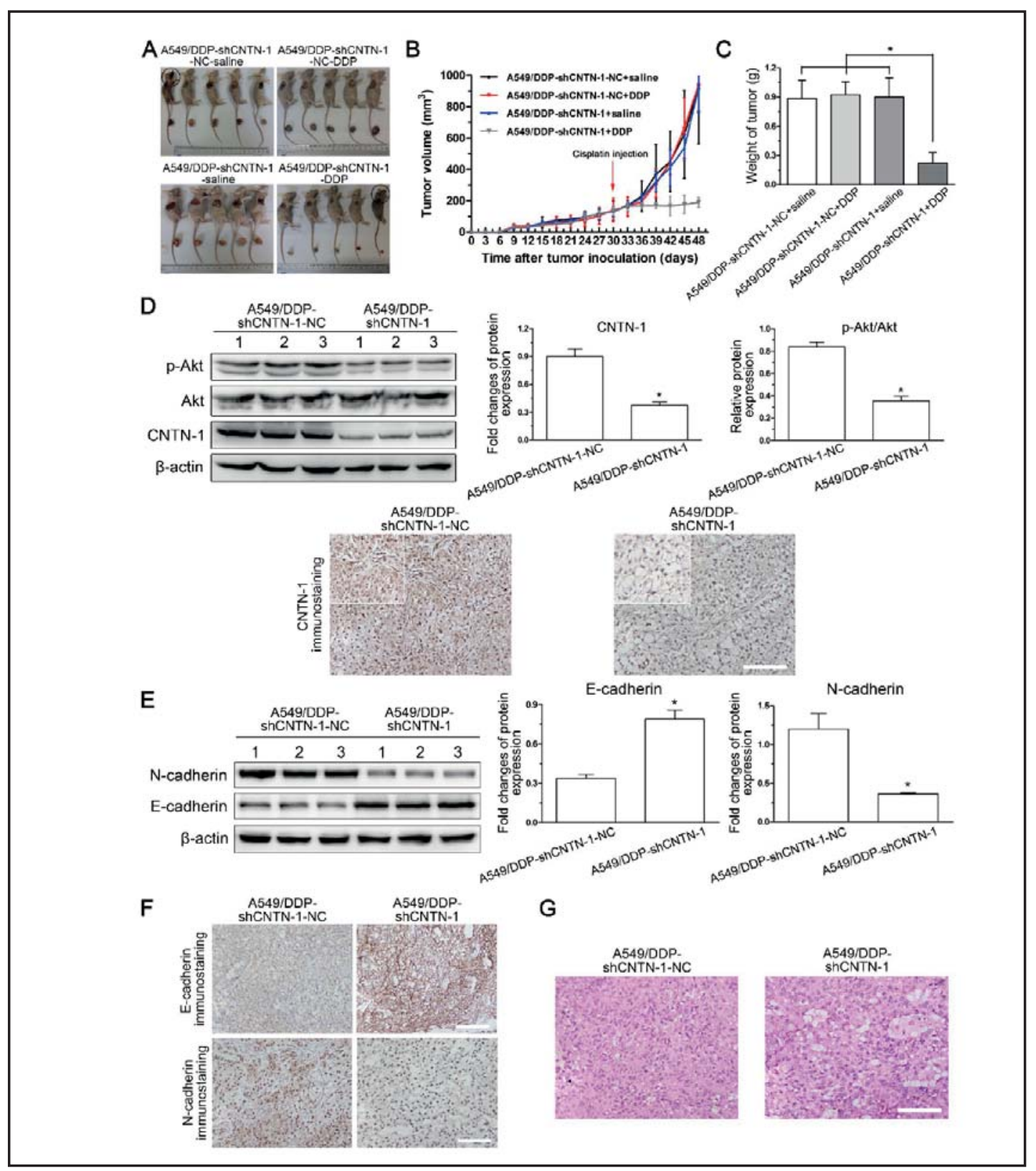

Fig. 6. Knockdown of contactin-1 (CNTN-1) reversed cisplatin resistance and the EMT phenotype of A549/ DDP cells in vivo. A: General observation of xenograft tumors in each subgroup treated with cisplatin or normal saline. Two black circles indicated that one mouse died two days before the endpoint of the experiment in the A549/DDP-shCNTN-1-NC-saline subgroup and that one mouse died one day before the endpoint of the experiment in the A549/DDP-shCNTN-1-DDP subgroup, respectively. B: Growth curves of xenograft tumors in each subgroup treated with cisplatin or normal saline. C: Measurement of the final tumor weight in each subgroup. D: Western blotting analysis and immunohistochemistry analysis of CNTN-1 expression and p-Akt expression in A549/DDP-shCNTN-1-NC-saline and A549/DDP-shCNTN-1-saline tumors. As shown in Fig. 6D, CNTN-1 exhibited a membrane or cytoplasmic localization (Magnification: $200 \times$, bar $=100 \mu \mathrm{m}$ ). $\mathrm{E}$ and F: Western blotting analysis and immunohistochemistry analysis of the expression of EMT-related markers (E-cadherin and N-cadherin) in A549/DDP-shCNTN-1-NC-saline and A549/DDP-shCNTN-1-saline tumors. Both E-cadherin and N-cadherin exhibited a membrane or cytoplasmic localization (Magnification: $200 \times$, bar $=100 \mu \mathrm{m}$ ). G: HE-staining observation on sections of saline-treated tumors (A549/DDP-shCNTN1-NC-saline and A549/DDP-shCNTN-1-saline). Magnification: 200x, bar $=100 \mu \mathrm{m}$ ). Data are expressed as the mean $\pm \operatorname{SD}(n=3)$. * significant difference between two groups $(\mathrm{p}<0.05)$. 


\section{Cellular Physiology \\ Cell Physiol Biochem 2017;43:465-480 \\ \begin{tabular}{ll|l} 
and Biochemisty & $\begin{array}{l}\text { DOI: 10.1159/000480473 } \\
\text { Published online: September 19, } 2017\end{array}$ & $\begin{array}{l}\text { (c) } 2017 \text { The Author(s). Published by S. Karger AG, Basel } \\
\text { www.karger.com/cpb }\end{array}$ \\
\hline
\end{tabular} \\ Zhang et al.: CNTN-1 Enhances Chemoresistance through Inducing EMT in Human Lung Adenocarcinoma}

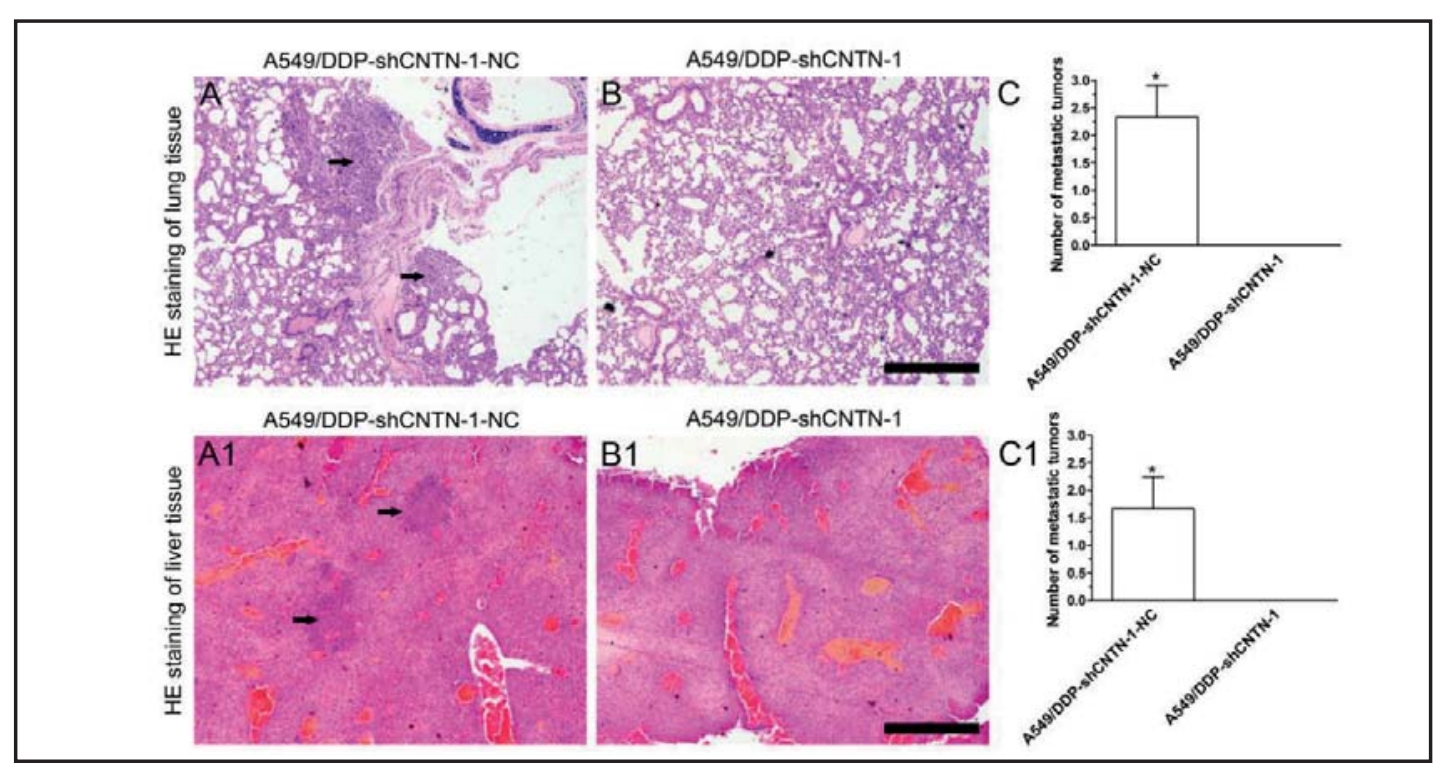

Fig. 7. Observation of the metastasis of A549/DDP-shCNTN-1-NC tumors and A549/DDP-shCNTN-1 tumors in lung (A-C) and liver (A1-C1) tissues. Black arrows indicate the metastatic tumors. Magnification: $100 \times$, bar $=200 \mu \mathrm{m}$.

\section{Discussion}

Despite the numerous achievements that have been obtained in the field of cancer therapy, platinum-based chemoresistance is still a main obstacle to the successful treatment of NSCLC [8]. Further exploration of the potential mechanisms of chemoresistance may help to address this challenge. Several recent studies reporting that CNTN-1 not only facilitates the metastasis of gastric cancer cells via activation of the EMT process [35], but also promotes drug resistance of lung adenocarcinoma [36] suggested that CNTN-1 might be a potential therapeutic target to inhibit malignant behaviors via mediating the EMT process in cisplatinresistant lung adenocarcinoma cells. To test this hypothesis, we carried out this study, and the findings demonstrated for the first time that CNTN-1 downregulation could inhibit cisplatin resistance and malignant progression via partly inactivating the EMT process by regulating the PI3K/Akt pathway, suggesting that CNTN-1 may be a potential target to reverse the malignant behaviors and improve chemotherapeutic efficiency in cisplatin-resistant lung adenocarcinoma.

CNTN-1 is an important molecule in nervous system development and maintenance [42]. Recently, CNTN-1 was demonstrated to be able to promote invasion, metastasis and proliferation in prostate cancer [43], thyroid cancer [44], gastric cancer [35, 45-46], lung cancer [32-33], esophageal squamous cancer [30, 47], and oral squamous cancer [31]. Additionally, in our previous studies, CNTN-1 was found to enhance the metastasis, invasion, and chemoresistance of lung cancer cells [36]. Based on these findings, we carried out a meta-analysis study that suggested that CNTN-1 might be a potential biomarker for tumor progression in carcinomas [48]. However, the mechanism behind the effects of CNTN-1 on cisplatin resistance in lung adenocarcinoma remains unclear.

EMT development is associated with an increase in migration, invasion, and anoikis tolerance in many malignancies [35, 49-51]. Moreover, EMT progression has been regarded as a novel mechanism for drug resistance in epithelial-originated malignancies [12-14, 40]. To test our hypothesis, first, the EMT phenotype was compared between A549/DDP cells and their progenitor A549 cells to evaluate the association of EMT development with cisplatin resistance. The results revealed that A549/DDP cells displayed an elongated and irregular fibroblastic morphology, while A549 cells exhibited an epithelial morphology characterized by a round shape and cluster growth (Fig. 1C) and verified by cytoskeleton 


\section{Cellular Physiology Cell Physiol Biochem 2017;43:465-480 \begin{tabular}{l|l|l} 
and Biochemistry & $\begin{array}{l}\text { DOI: 10.1159/000480473 } \\
\text { Published online: September 19, } 2017\end{array}$ & $\begin{array}{l}\text { @ } 2017 \text { The Author(s). Published by S. Karger AG, Basel } \\
\text { www.karger.com/cpb }\end{array}$ \\
\hline
\end{tabular} \\ Zhang et al:: CNTN-1 Enhances Chemoresistance through Inducing EMT in Human Lung Adenocarcinoma}

F-actin staining (Fig. 1D) and the detection of EMT-related markers (Fig. 1E-F), indicating that the EMT phenotype was correlated with the cisplatin resistance of lung adenocarcinoma. Additionally, the EMT phenotype promoted the malignant progression in cisplatin-resistant lung adenocarcinoma cells, reflected by the observation that the migration (Fig. 2A), invasion (Fig. 2B), and anoikis resistance (Fig. 2C-D) of A549/DDP cells were significantly greater than A549 cells. Moreover, pluripotent markers (CD44, OCT-4, and Nanog) were upregulated in A549/DDP cells compared with those in A549 cells (Fig. 2E). Collectively, these findings suggest that cisplatin-resistant lung adenocarcinoma cells with an EMT phenotype display aggravated tumor malignant behaviors.

To explore the role of CNTN- 1 in the EMT process and cisplatin resistance, CNTN-1 was overexpressed in A549 cells and silenced in A549/DDP cells. The results demonstrated that the overexpression of CNTN-1 in A549 cells (A549-CNTN-1) promoted EMT progression and enhanced malignant behaviors (including metastasis, invasion, cisplatin resistance, and anoikis resistance) compared with that observed with control (A549-CNTN-1-NC) cells, whereas silencing CNTN-1 in A549/DDP cells (A549/DDP-shCNTN-1) reversed the EMT phenotype and inhibited malignant behaviors compared with that observed in A549/DDPshCNTN-1-NC cells, indicating that CNTN-1 expression was related to EMT development and the malignant progression of cisplatin-resistant lung adenocarcinoma cells, and CNTN-1 overexpression in A549/DDP cells may make the cisplatin-resistant cells more resistant to cisplatin and display a more aggressive EMT phenotype.

The PI3K/Akt signaling pathway is a key pathway that regulates the EMT process, cell proliferation, survival, migration, and invasion [39-40]. Activation of the Akt signaling pathway has not only been reported to be involved in TGF- $\beta$-induced EMT development [52], but also in increasing snail expression and inducing EMT development through phosphorylation of IKK $\alpha$ [52]. Moreover, activation of Akt signaling is also related with the chemoresistance of tumor cells [53-54]. In this study, p-Akt was significantly higher in A549/DDP cells than in A549 cells, which was reversed by CNTN-1 silencing, suggesting that CNTN-1 is the upstream molecule regulating the PI3K/Akt signaling pathway. Because knockdown of p-Akt is hard to achieve, a specific inhibitor, LY294002, was used to investigate the role of the PI3K/Akt pathway in this study. We found that when the PI3K/Akt pathway in A549/DDP cells was inhibited by LY294002, the EMT phenotype was partly reversed, and the malignant behaviors were attenuated, strongly suggesting that the PI3K/Akt signaling pathway is a crucial pathway that regulates the EMT process and the malignant progression of lung adenocarcinoma, which is partly mediated by CNTN-1.

Because the study was aimed to investigate whether the PI3K/Akt pathway is involved in the CNTN-1-mediated EMT process and the resulting cisplatin resistance in A549/DDP cells, we did not explore how CNTN-1 activates the PI3K/Akt pathway in this study. However, prior studies have provided us two main potential mechanisms. One of which is that CNTN-1 enhances AKT activation in part by preventing PHLPP2-mediated AKT dephosphorylation [33]. The other is that CNTN-1 can bind to the receptor protein tyrosine phosphatases gamma zeta (PTPRZ) through its structural CA domains [55], given that CNTN-1 has six Ig domains, four fibronectin-like motifs, and a glycosyl phosphatidylinositol (GPI) moiety [28]. To clearly understand this process, further studies are needed in the future.

To evaluate the potential of CNTN-1 to reverse the EMT phenotype and cisplatin resistance of lung adenocarcinoma cells in clinical practice, a xenograft mouse model was established, and the data revealed that along the course of the experiment, further growth of the A549/DDP-shCNTN-1 tumors treated with DDP was significantly prevented compared with that of A549/DDP-shCNTN-1 tumors treated with saline and that of A549/DDP-shCNTN1-NC tumors treated with DDP and saline. Additionally, consistent with the previous studies that showed that CNTN-1 silencing dramatically increased cisplatin sensitivity without affecting cell proliferation [34, 36], no significant difference in the sizes of the saline-treated A549/DDP-shCNTN-1 tumors and the saline-treated A549/DDP-shCNTN-1-NC tumors was detected in the animal model, suggesting that CNTN-1 contributes to the cisplatin resistance rather than tumor growth of lung adenocarcinoma cells (Fig. 6A-C). Additionally, the findings 


\section{Cellular Physiology Cell Physiol Biochem 2017;43:465-480 \\ \begin{tabular}{ll|l} 
and Biochemistry $10.1159 / 000480473$ & $\begin{array}{l}\text { C) } 2017 \text { The Author(s). Published by S. Karger AG, Base } \\
\text { www.karger.com/cpb }\end{array}$ \\
\cline { 1 - 3 }
\end{tabular} \\ Zhang et al:: CNTN-1 Enhances Chemoresistance through Inducing EMT in Human Lung Adenocarcinoma}

that the tumors developed with A549/DDP-shCNTN-1 cells grew very slowly after cisplatin treatment revealed that although CNTN-1 contributes to the cisplatin resistance of A549/ DDP cells, other genes might also be involved in the cisplatin resistance of A549/DDP cells. Moreover, the results showed that mesenchymal marker (N-cadherin) expression was lower, whereas expression of epithelial marker (E-cadherin) was higher in A549/DDP-shCNTN1-saline tumors than in A549/DDP-shCNTN-1-NC-saline tumors (Fig. 6E-F). Furthermore, HE staining showed a reversal of the EMT-related cellular morphology in A549/DDPshCNTN-1 tumors (Fig. 6G). These results further confirm that CNTN-1 contributes to the EMT phenotype in cisplatin-resistant lung adenocarcinoma cells.

Although we report for the first time that CNTN-1 contributed to the EMT phenotype and resulting cisplatin resistace and malignant progression of lung adenocarcinoma, some limitations still exist in our research. First, we were unable to evaluate the role of CNTN-1 in patients with lung adenocarcinoma due to the difficulties in collecting adequate cisplatinresistant samples in clinical practice to verify the findings of the CNTN-1 modulation of the EMT process, cisplatin resistance, and tumor malignant behaviors obtained from the cell model and animal model. Second, the mouse model of the study was only done with a resistant cell line. Furthermore, although short-term cisplatin treatment was shown to prevent further growth of A549/DDP-shCNTN-1-DDP tumors, whether long-term cisplatin treatment has the same effects requires further investigation. Third, although the experiments of CNTN-1 overexpression in A549 cells and CNTN-1 knockdown in A549/DDP cells indicated a positive role of CNTN-1 in promoting cisplatin resistance, increasing the level of CNTN-1 expression in A549/DDP cells was not performed, but this additional experiment may further back up our conclusion.

In conclusion, the present study showed that CNTN-1 upregulation promotes the malignant progression (including metastasis, invasion, and drug resistance) of cisplatinresistant lung adenocarcinoma cells through inducing an EMT phenotype by activating the PI3K/Akt signaling pathway, which strongly suggests that CNTN-1 may be a potential therapeutic target to reverse the malignant progression in cisplatin-resistant lung adenocarcinoma cells.

\section{Acknowledgements}

This work is supported by grants from the Central South University Innovation Foundation for Postgraduates (2016zzts157) and National Natural Science Foundation of China (81372499 and 81601932).

\section{Disclosure Statement}

The authors declare that they have no conflicts of interest.

\section{References}

- Hong QY, Wu GM, Qian GS, Hu CP, Zhou JY, Chen LA, Li WM, Li SY, Wang K, Wang Q, Zhang XJ, Li J, Gong X, Bai CX, Lung Cancer Group of Chinese Thoracic S, Chinese Alliance Against Lung C: Prevention and management of lung cancer in China. Cancer 2015;121 Suppl 17:3080-3088.

2 Wang H, Liu X, Rice SJ, Belani CP: Pulmonary Rehabilitation in Lung Cancer. PM R 2016;8:990-996.

3 Balgkouranidou I, Liloglou T, Lianidou ES: Lung cancer epigenetics: emerging biomarkers. Biomark Med 2013;7:49-58.

4 Leon G, MacDonagh L, Finn SP, Cuffe S, Barr MP: Cancer stem cells in drug resistant lung cancer: Targeting cell surface markers and signaling pathways. Pharmacol Ther 2016;158:71-90.

-5 Fennell DA, Summers Y, Cadranel J, Benepal T, Christoph DC, Lal R, Das M, Maxwell F, Visseren-Grul C, Ferry D: Cisplatin in the modern era: The backbone of first-line chemotherapy for non-small cell lung cancer. Cancer Treat Rev 2016;44:42-50. 


\section{Cellular Physiology Cell Physiol Biochem 2017;43:465-480 \begin{tabular}{ll|l} 
and Biochemistry & $\begin{array}{l}\text { DOI: 10.1159/000480473 } \\
\text { Published online: September 19, } 2017\end{array}$ & $\begin{array}{l}\text { C) } 2017 \text { The Author(s). Published by S. Karger AG, Base } \\
\text { www.karger.com/cpb }\end{array}$ \\
\hline
\end{tabular} \\ Zhang et al.: CNTN-1 Enhances Chemoresistance through Inducing EMT in Human Lung Adenocarcinoma}

6 Wen G, Qu XX, Wang D, Chen XX, Tian XC, Gao F, Zhou XL: Recent advances in design, synthesis and bioactivity of paclitaxel-mimics. Fitoterapia 2016;110:26-37. Shi Y, Sun Y: Medical management of lung cancer: Experience in China. Thorac Cancer 2015;6:10-16.

8 Amable L: Cisplatin resistance and opportunities for precision medicine. Pharmacol Res 2016;106:27-36

-9 Galluzzi L, Vitale I, Michels J, Brenner C, Szabadkai G, Harel-Bellan A, Castedo M, Kroemer G: Systems biology of cisplatin resistance: past, present and future. Cell Death Dis 2014;5:e1257.

10 Johnstone RW, Ruefli AA, Lowe SW: Apoptosis: a link between cancer genetics and chemotherapy. Cell 2002;108:153-164.

11 Tan Q, Cui J, Huang J, Ding Z, Lin H, Niu X, Li Z, Wang G, Luo Q, Lu S: Genomic Alteration During Metastasis of Lung Adenocarcinoma. Cell Physiol Biochem 2016;38:469-486.

-12 Shang Y, Cai X, Fan D: Roles of epithelial-mesenchymal transition in cancer drug resistance. Curr Cancer Drug Targets 2013;13:915-929.

13 Mitra A, Mishra L, Li S: EMT, CTCs and CSCs in tumor relapse and drug-resistance. Oncotarget 2015;6:10697-10711.

-14 Voulgari A, Pintzas A: Epithelial-mesenchymal transition in cancer metastasis: mechanisms, markers and strategies to overcome drug resistance in the clinic. Biochim Biophys Acta 2009;1796:75-90.

15 Smith BN, Bhowmick NA: Role of EMT in Metastasis and Therapy Resistance. J Clin Med 2016;5:

-16 Cai M, Wang Z, Zhang J, Zhou H, Jin L, Bai R, Weng Y: Adam17, a Target of Mir-326, Promotes Emt-Induced Cells Invasion in Lung Adenocarcinoma. Cell Physiol Biochem 2015;36:1175-1185.

17 Ma JL, Zeng S, Zhang Y, Deng GL, Shen H: Epithelial-mesenchymal transition plays a critical role in drug resistance of hepatocellular carcinoma cells to oxaliplatin. Tumour Biol 2016;37:6177-6184.

- 18 Bao Y, Lu Y, Wang X, Feng W, Sun X, Guo H, Tang C, Zhang X, Shi Q, Yu H: Eukaryotic translation initiation factor 5A2 (eIF5A2) regulates chemoresistance in colorectal cancer through epithelial mesenchymal transition. Cancer Cell Int 2015;15:109.

19 Zhou Z, Zhang L, Xie B, Wang X, Yang X, Ding N, Zhang J, Liu Q Tan G, Feng D, Sun LQ: FOXC2 promotes chemoresistance in nasopharyngeal carcinomas via induction of epithelial mesenchymal transition. Cancer Lett 2015;363:137-145.

20 Yang Q, Huang J, Wu Q Cai Y, Zhu L, Lu X, Chen S, Chen C, Wang Z: Acquisition of epithelial-mesenchymal transition is associated with Skp2 expression in paclitaxel-resistant breast cancer cells. Br J Cancer 2014;110:1958-1967.

21 Lu WD, Zuo Y, Xu Z, Zhang M: MiR-19a promotes epithelial-mesenchymal transition through PI3K/AKT pathway in gastric cancer. World J Gastroenterol 2015;21:4564-4573.

22 Wang SC, Chai DS, Chen CB, Wang ZY, Wang L: HPIP promotes thyroid cancer cell growth, migration and EMT through activating PI3K/AKT signaling pathway. Biomed Pharmacother 2015;75:33-39.

-23 Zhao QY, Ju F, Wang ZH, Ma XZ, Zhao H: ING5 inhibits epithelial-mesenchymal transition in breast cancer by suppressing PI3K/Akt pathway. Int J Clin Exp Med 2015;8:15498-15505.

- 24 Dong P, Konno Y, Watari H, Hosaka M, Noguchi M, Sakuragi N: The impact of microRNA-mediated PI3K/AKT signaling on epithelial-mesenchymal transition and cancer stemness in endometrial cancer. J Transl Med 2014;12:231.

25 Danielsen SA, Eide PW, Nesbakken A, Guren T, Leithe E, Lothe RA: Portrait of the PI3K/AKT pathway in colorectal cancer. Biochim Biophys Acta 2015;1855:104-121.

-26 Papadimitrakopoulou V: Development of PI3K/AKT/mTOR pathway inhibitors and their application in personalized therapy for non-small-cell lung cancer. J Thorac Oncol 2012;7:1315-1326.

27 Cheaib B, Auguste A, Leary A: The PI3K/Akt/mTOR pathway in ovarian cancer: therapeutic opportunities and challenges. Chin J Cancer 2015;34:4-16.

-28 Berglund EO, Ranscht B: Molecular cloning and in situ localization of the human contactin gene (CNTN1) on chromosome 12q11-q12. Genomics 1994;21:571-582.

29 Haenisch C, Diekmann H, Klinger M, Gennarini G, Kuwada JY, Stuermer CA: The neuronal growth and regeneration associated Cntn1 (F3/F11/Contactin) gene is duplicated in fish: expression during development and retinal axon regeneration. Mol Cell Neurosci 2005;28:361-374.

- 30 Liu P, Chen S, Wu W, Liu B, Shen W, Wang F, He X, Zhang S: Contactin-1 (CNTN-1) overexpression is correlated with advanced clinical stage and lymph node metastasis in oesophageal squamous cell carcinomas. Jpn J Clin Oncol 2012;42:612-618.

-31 Wu HM, Cao W, Ye D, Ren GX, Wu YN, Guo W: Contactin 1 (CNTN1) expression associates with regional lymph node metastasis and is a novel predictor of prognosis in patients with oral squamous cell carcinoma. Mol Med Rep 2012;6:265-270. 


\section{Cellular Physiology Cell Physiol Biochem 2017;43:465-480 \\ \begin{tabular}{ll|l} 
and Biochemistry Published online: September 19, 2017 & $\begin{array}{l}\text { O } 2017 \text { The Author(s). Published by S. Karger AG, Base } \\
\text { www.karger.com/cpb }\end{array}$ \\
\hline
\end{tabular}}

Zhang et al.: CNTN-1 Enhances Chemoresistance through Inducing EMT in Human Lung Adenocarcinoma

-32 Su JL, Yang CY, Shih JY, Wei LH, Hsieh CY, Jeng YM, Wang MY, Yang PC, Kuo ML: Knockdown of contactin-1 expression suppresses invasion and metastasis of lung adenocarcinoma. Cancer Res 2006;66:2553-2561.

-33 Yan J, Wong N, Hung C, Chen WX, Tang D: Contactin-1 reduces E-cadherin expression via activating AKT in lung cancer. PLoS One 2013;8:e65463.

- 34 Su JL, Yang PC, Shih JY, Yang CY, Wei LH, Hsieh CY, Chou CH, Jeng YM, Wang MY, Chang KJ, Hung MC, Kuo ML: The VEGF-C/Flt-4 axis promotes invasion and metastasis of cancer cells. Cancer Cell 2006;9:209-223.

- 35 Chen DH, Yu JW, Wu JG, Wang SL, Jiang BJ: Significances of contactin-1 expression in human gastric cancer and knockdown of contactin-1 expression inhibits invasion and metastasis of MKN45 gastric cancer cells. J Cancer Res Clin Oncol 2015;141:2109-2120.

-36 Zhang R, Yao W, Qian P, Li Y, Jiang C, Ao Z, Qian G, Wang C, Wu G, Li J, Ji F, Xu J: Increased sensitivity of human lung adenocarcinoma cells to cisplatin associated with downregulated contactin-1. Biomed Pharmacother 2015;71:172-184.

37 Guo R, Wu G, Li H, Qian P, Han J, Pan F, Li W, Li J, Ji F: Promoter methylation profiles between human lung adenocarcinoma multidrug resistant A549/cisplatin (A549/DDP) cells and its progenitor A549 cells. Biol Pharm Bull 2013;36:1310-1316.

- 38 Naito S vEA, Giavazzi R, Fidler IJ: Growth and metastasis of tumor cells isolated from a human renal cell carcinoma implanted into different organs of nude mice. Cancer Res 1986;46:4109-4115.

-39 Nantajit D, Lin D, Li JJ: The network of epithelial-mesenchymal transition: potential new targets for tumor resistance. J Cancer Res Clin Oncol 2015;141:1697-1713.

40 Sui H, Zhu L, Deng W, Li Q: Epithelial-mesenchymal transition and drug resistance: role, molecular mechanisms, and therapeutic strategies. Oncol Res Treat 2014;37:584-589.

-41 Tang KD, Ling MT: Targeting drug-resistant prostate cancer with dual PI3K/mTOR inhibition. Curr Med Chem 2014;21:3048-3056.

42 Mohebiany AN, Harroch S, Bouyain S: New insights into the roles of the contactin cell adhesion molecules in neural development. Adv Neurobiol 2014;8:165-194.

43 Yan J, Ojo D, Kapoor A, Lin X, Pinthus JH, Aziz T, Bismar TA, Wei F, Wong N, De Melo J, Cutz JC, Major P, Wood G, Peng H, Tang D: Neural Cell Adhesion Protein CNTN1 Promotes the Metastatic Progression of Prostate Cancer. Cancer Res 2016;76:1603-1614.

-44 Shi K, Xu D, Yang C, Wang L, Pan W, Zheng C, Fan L: Contactin 1 as a potential biomarker promotes cell proliferation and invasion in thyroid cancer. Int J Clin Exp Pathol 2015;8:12473-12481.

-45 Yu JW, Wu SH, Lu RQ, Wu JG, Ni XC, Zhou GC, Jiang HG, Zheng LH, Li XQ, Du GY, Jiang BJ: Expression and significances of contactin-1 in human gastric cancer. Gastroenterol Res Pract 2013;2013:210205.

46 Chen DH, Yu JW, Jiang BJ: Contactin 1: A potential therapeutic target and biomarker in gastric cancer. World J Gastroenterol 2015;21:9707-9716.

-47 Liu P, Zhou J, Zhu H, Xie L, Wang F, Liu B, Shen W, Ye W, Xiang B, Zhu X, Shi R, Zhang S: VEGF-C promotes the development of esophageal cancer via regulating CNTN-1 expression. Cytokine 2011;55:8-17.

48 Zhang R, Xie L, Liu C, Yang H, Lin H, Zhang Q, Tang W, Ji F, Sun S: Contactin-1: a promising progression biomarker and therapeutic target of carcinoma. Minerva Med 2017;108:193-195.

-49 Ekpe-Adewuyi E, Lopez-Campistrous A, Tang X, Brindley DN, McMullen TP: Platelet derived growth factor receptor alpha mediates nodal metastases in papillary thyroid cancer by driving the epithelialmesenchymal transition. Oncotarget 2016;7:83684-83700.

-50 Chong Y, Tang D, Gao J, Jiang X, Xu C, Xiong Q Huang Y, Wang J, Zhou H, Shi Y, Wang D: Galectin-1 induces invasion and the epithelial-mesenchymal transition in human gastric cancer cells via non-canonical activation of the hedgehog signaling pathway. Oncotarget 2016;7:83611-83626.

-51 Xu X, Yan Q, Wang Y, Dong X: NTN4 is associated with breast cancer metastasis via regulation of EMTrelated biomarkers. Oncol Rep 2017;37:449-457.

-52 Larue L, Bellacosa A: Epithelial-mesenchymal transition in development and cancer: role of phosphatidylinositol 3' kinase/AKT pathways. Oncogene 2005;24:7443-7454.

53 Yang H, He L, Kruk P, Nicosia SV, Cheng JQ: Aurora-A induces cell survival and chemoresistance by activation of Akt through a p53-dependent manner in ovarian cancer cells. Int J Cancer 2006;119:23042312.

-54 Yang X, Fraser M, Moll UM, Basak A, Tsang BK: Akt-mediated cisplatin resistance in ovarian cancer: modulation of p53 action on caspase-dependent mitochondrial death pathway. Cancer Res 2006;66:31263136.

55 Bouyain S, Watkins DJ: The protein tyrosine phosphatases PTPRZ and PTPRG bind to distinct members of the contactin family of neural recognition molecules. Proc Natl Acad Sci U S A 2010;107:2443-2448. 